\title{
THAT OBSCURE OBJECT OF DESIRE: THE MANAGEMENT OF ACADEMIC KNOWLEDGE
}

\begin{abstract}
For academic administrators, the management of research remains a matter more of hope than expectation. It has proved particularly difficult to measure quality. Managers typically view research as an 'asset'. This essay argues that it is more useful to view research and its management as 'process', and explores the implications of doing so for managers and researchers alike.
\end{abstract}

\section{INTRODUCTION}

The globalization, commercialization, and marketing of knowledge have increased pressures on research managers and academics in many ways. ${ }^{1}$ Academia has become more transparent, more accountable, and more goal-driven. Quality assessment is now commonplace in every industrialized country. ${ }^{2}$ However, the policy and management literature rarely concerns itself with the practice of research. ${ }^{3}$ Yet, these practices and expectations shape the production of knowledge. The aim of this paper is to explore how certain images of knowledge appear in 'quality management', how research managers perceive quality, and how they go about managing it.

\section{Knowledge of Quality and Quality of Knowledge}

Concepts of 'quality' are integral to research management. Yet, we have no definition of quality that is both comprehensive and

\footnotetext{
${ }^{1}$ See, for instance, L. Morley, Quality and Power in Higher Education (Buckingham: Open University Press, 2003); M. Gibbons, C. Limoges, H. Nowotny, S. Schwartzman, P. Scott, and M. Trow, The New Production of Knowledge: The Dynamics of Science and Research in Contemporary Societies (London: Sage, 1994); and H. Nowotny, P. Scott, and M. Gibbons, Rethinking Science: Knowledge and the Public in an Age of Uncertainty (Cambridge: Polity, 2001).

${ }^{2}$ Y. Fujigaki and L. Leydesdorff, 'Quality Control and Validation Boundaries in a Triple Helix of University-Industry-Government: "Mode 2" and the Future of University Research', Social Science Information, 39 (4), (2000), 635-655.

${ }^{3}$ Exceptions are N. Morris, 'Science Policy in Action: Policy and the Researcher', Minerva, 38 (4), (2000), 425-451; R.D. Whitley, The Intellectual and Social Organization of the Sciences (Oxford: Oxford University Press, 2000), and N. Morris, 'The Developing Role of Departments', Research Policy, 31 (5), (2002), 817-833.
} 
undisputed. ${ }^{4}$ A commonsensical definition refers to "the standard of something when compared to other things like it'. 5 This definition draws attention to 'standards'. But this assumes that one knows how standards are established. Attempts to tag standards specify quantifiable measures. Some argue that even quantifiable standards cannot be objective. ${ }^{6}$ Qi $\mathrm{Xu}$ maintains that approaches equating quality with quantifiable benchmarks typically fail to recognize its constructed, situated, and negotiated character. ${ }^{7}$ Others say that even objective quantifiable outcomes are not necessarily indicators of quality. ${ }^{8}$ Indeed, Michael Power argues that negotiation is essential: 'quality is not about high standards but about those that are uniform, predictable and verifiable'.

In this way, the idea of 'quality' emerges as a constructed archetype, subject to negotiation, and bounded by history and culture. Linking the idea of quality to research management immediately exacerbates the problem of definition. Research is surrounded by ambiguity. Even to attempt the management of academic research may be counterproductive, because it forces purpose on an activity that defines its own purpose.

Unsurprisingly, there are differences between the ways in which managers view quality, as embedded in assessment and reward policies, and how researchers view the same object. ${ }^{10} \mathrm{We}$ also know

\footnotetext{
${ }^{4}$ For an overview of definitions, see K. Cameron and D.A. Whetten, 'Organizational Effectiveness and Quality: The Second Generation,' in J.C. Smart (ed.), Higher Education: Handbook of Theory and Research (New York: Agathon, 1996), 265-306.

5 Oxford Advanced Learner's Dictionary (Oxford: Oxford University Press, 7th ed., 2004).

${ }^{6}$ For instance, see Morley, op. cit. note 1; W.N. Espeland and M.L. Stevens, 'Commensuration as a Social Process', Annual Review of Sociology, 24 (1998), 313-343., and M. Power, 'Counting, Control and Calculation: Reflections on Measuring and Management', Human Relations, 57 (6), (2004), 765-783.

${ }^{7}$ Q. Xu, 'TQM as an Arbitrary Sign for Play: Discourse and Transformation', Organization Studies, 20 (4), (1999), 659-681.

${ }^{8}$ C. Ewan and D. Calvert, 'The Crisis of Scientific Research', in J. Garrick and C. Rhodes (eds.), Research and Knowledge at Work: Perspectives, Case-studies and Innovative Strategies (London: Routledge, 2000), 51-74.

${ }_{9}^{9}$ Michael Power, The Audit Society: Rituals of Verification (New York: Oxford University Press, 1997), 59.

${ }^{10}$ W.H. Lambright and A.H. Teich, 'The Organizational Context of Scientific Research', in P.C. Nystrom and W.H. Starbuck (eds.), Handbook of Organizational Design (Oxford: Oxford University Press, 1981), 305-319. Even if scientists agree on disciplinary boundaries, institutional boundaries may still be subject to dispute because these may be linked to management objectives, or to competition between disciplines or subdisciplines, For academic fields characterized by competing paradigms, or featuring 'Mode-2' knowledge production, establishing such boundaries may be even more difficult.
} 
that attempts to assess quality yield different outcomes in different disciplines and different contexts. ${ }^{11}$

This paper considers these questions as they arise in the discipline of business administration, and in the context of The Netherlands. ${ }^{12}$ In this discipline, which combines applied and fundamental research, there has been little systematic exploration of 'quality management' in terms of 'knowledge management'. ${ }^{13}$ From the research manager's point of view, publication in international journals is valued over publication in books, partly because of the discipline's close ties with economics, and partly because of a need to distinguish fundamental science from commercial consultancy. In this context, publication in ISI journals is valued highly. However, this measure is problematic. Richard Whitley notes that, unlike economics, business studies is typified by high levels of task uncertainty. He describes the field as a 'fragmented ad-hocracy', and he may be right. ${ }^{14}$ How best to understand its reaction to the increasingly invasive demands of research managers?

\section{BUSINESS ADMINISTRATION IN THE NETHERLANDS}

To explore this question, we selected a set of Dutch institutes that have research programmes in business administration and management studies. In most cases, these programmes have coordinators who report to a research director, who in turn reports to a Dean of

\footnotetext{
${ }_{11}$ Whitley, op. cit. note 3 .

12 The Netherlands provides an interesting setting for a case study because it occupies a middle position between Germany, where signs of ex-post research performance assessment are just beginning to surface, and the United Kingdom, where it is proposed that the Research Assessment Exercise (RAE) be fully based on such methods. See A. Geuna and B.R. Martin, 'University Research Evaluation and Funding: An International Comparison', Minerva, 41 (4), (2003), 277-304.

${ }^{13}$ Several studies address management issues in the field of business administration. See M.J. Jones, T. Brinn, and M. Pendlebury, 'Judging the Quality of Research in Business Schools: A Comment from Accounting', Omega-International Journal of Management Science, 24 (5), (1996), 597-602; A.S. Huff and J.O. Huff, 'Re-focusing the Business School Agenda', British Journal of Management, 12 (special issue, December 2001), S49-S54; K. Starkey and P. Madan, 'Bridging the Relevance Gap: Aligning Stakeholders in the Future of Management Research', idem., S3-S26; K. Starkey, A. Hatchuel, and S. Tempest, 'Rethinking the Business School', Journal of Management Studies, 41 (8), (2004), 1521-1531; M. Muller-Camen and S. Salzgeber, 'Changes in Academic Work and the Chair Regime: The Case of German Business Administration Academics', Organization Studies, 26 (2), (2005), 271-290; and K. Starkey and S. Tempest, 'The Future of the Business School: Knowledge Challenges and Opportunities', $\mathrm{Hu}$ man Relations, 58 (1), (2005), 61-82.

${ }^{14}$ Whitley, op. cit. note 3 .
} 
the Faculty. The research director delineates overall strategy, whilst the programme coordinators organize work at a project group level. Since we promised confidentiality, we cannot identify the institute or research group by name, but we will give a general description of the source in each case.

The main study, which took place between March 2003 and August 2004, involved interviews with twenty-nine research coordinators. $^{15}$ The interviews asked three questions: (1) why research quality is measured? (2) how evaluation is performed? and (3) what effects this process has on research? The interviews also showed that a fourth question, what is (research) quality? also must be asked. Following the 'grounded theory approach', we compared codes, patterns, properties, associations, and possible relationships between concepts. ${ }^{16}$ Information was compiled, based on the independent interpretations of both authors.

\section{Question I: What is Research Quality? Quality as Credentialized Judgement}

Answers to the first question revealed widely differing understandings of research, of research quality, and of the purpose of asking these questions in the first place. Several respondents pointed to the importance of disciplinary boundaries in framing such questions. Those who did try to explain 'what defines quality' almost invariably saw quality not as a given, neutral, or stable attribute, but rather as an extrinsic, subjective, and unsettled perception. As one coordinator from a large, successful institute suggested:

Research quality is a very difficult thing to establish; its scientific value and its scientific relevance are the two main issues. Since the research process is very subjective, every researcher will have a different idea about this. What we seek to have is a more objective scientific result. By scientific, I mean that the result can be shared independently of the individual. If both the research process and the result are purely subjective, the result is personal knowledge, experience or something

\footnotetext{
${ }^{15}$ The decision to end interviews with the twenty-nine research coordinators was based on considerations of diminishing returns.

${ }^{16}$ See B.G. Glaser and A.L. Strauss, The Discovery of Grounded Theory: Strategies for Qualitative Research (Chicago: Aldine, 1967). The 'grounded theory approach' (GTA) is a methodology for generating theory from a comparison of data. GTA has been widely applied to studies of professional work carried out in complex organizations, making it particularly appropriate for studying managerial and organizational behaviour. See K.D. Locke, Grounded Theory in Management Research (London: Sage Publications, 2001).
} 
else, but certainly not scientific knowledge. Apparently, these are different things. The difference between personal and scientific knowledge has to do with objectivity, i.e., personal independence. It is a kind of objectivity that turns into value. ${ }^{17}$

This coexistence of differing perceptions may partly explain why managers have evolving ideas of what research quality is, can be, or should be. As one research director explained:

Overall, it is very difficult to say what scientific quality really is. For me, it implies that the ideas conveyed in a contribution are really pathbreaking and that they really open new avenues for research. The implicit assumption is that because these ideas are pathbreaking they are recognized by the research community and thereby receive attention expressed in terms of citations. ${ }^{18}$

However, defining precisely what 'pathbreaking' means, and how 'new avenues for research' are to be built, does not eliminate dispute, but merely displaces it. The conceptual borders of the term 'quality' emerge as porous, evolving, contested, provisional, subjective, political, historical, and community-dependent. The disciplines may not have a problem with this. But when the need arises to establish quality assessments at the institutional level, agreement proves difficult.

\section{Question II - Why Measure Quality? Between Rationalization and Credentialization}

The question 'Why do you measure research quality?' unpacked two key motives: rationalization and credentialization. Rationalization represents the effective and efficient use of resources, whilst credentialization refers to the formalization of reputation. ${ }^{19}$

\section{Rationalization}

Everyone recognizes the need to allocate resources on the basis of performance. In so doing, however, a process of rationalization is needed - first, to establish quality standards against which research

\footnotetext{
${ }^{17}$ Defining 'success', as is done here, draws upon the most recent national assessment of Business Administration in The Netherlands, which has evaluated individual research programmes as 'excellent', 'very good', 'good', 'satisfactory', or 'unsatisfactory'. The institutes submitted between three and eight programmes. If an institute's programmes were all assessed as 'excellent' or 'very good', that institute we labelled as 'highly successful'. Institutes assessed as 'good', we have labelled 'successful'. If an institute had at least one 'satisfactory' or 'unsatisfactory' programme, but also at least one 'good' programme, it is labelled as 'an institute with a mixed record of success'. All institutes received at least one 'good' assessment.

${ }^{18}$ Respondent from a large, highly successful institute. To define 'success', see note 17.

19 The term 'credentialization' is an umbrella term that refers to the institutionalised recognition of personal or organizational ability, quality, or suitability. One of the forms this takes is accreditation.
} 
can be evaluated; and second, to use evaluation as a mechanism for allocation. As one coordinator explained:

Research quality is evaluated because you need to allocate budgets - you want to have a good performance per euro or hour - and to be able to reward the people who are better, while giving a signal to those who are under-performing. ${ }^{20}$

Rationalization is, therefore, not just a parsimonious imperative, but also a method of performance appraisal, rewarding those who follow the norms and punishing those who fail to do so. Put briefly, rationalization follows a Benthamite precept, connecting appraisal with budgeting. In the words of a second coordinator:

Essentially, the board of the university seeks to have mechanisms to ensure good money allocation and application. Part of the money for the groups that did not score high enough can be diverted to our top research institutes and to top researchers, which will actually further their position. With this, the lowperforming groups get an incentive to work harder. ${ }^{21}$

As we found, managerial rhetoric is used to bring about cultural change in problem-choice research evaluation. This reconfiguration is not trivial because it signals the changing conditions of research from a simple, or representative republic of science, to a domain of elitism and privilege. As a third coordinator argued:

Dutch academics used to have $50 \%-50 \%$ teaching-research time. This rested on the idea that everyone had similar qualities and that everyone was equally successful in terms of teaching and research. Yet we know that this is not true. Providing that we accept that people are not all equal, and that some may have to do more teaching while others more research, we need criteria to measure their achievements. ${ }^{22}$

In this process, ingrained principles of equality are being replaced by mechanisms designed to reward compliance and discourage dissent. Closely associated with the principle of rationalization is the principle of discrimination. Research institutes appear to have adopted this principle, in the absence of an easily defined exchange value for science. As a research director of a 'relatively small institute with a record of mixed success' put it:

In the end, this is an economic affair. There are limited resources, thus it seems reasonable to spend this sum as effectively and efficiently as possible. This is the main reason why we try to measure quality. With normal goods, there is a market to perform the job. We measure quality because there is no market for scientific knowledge.

\footnotetext{
${ }^{20}$ Respondent from a relatively small institute with a record of mixed success. See note 17.

${ }^{21}$ Respondent from a large, successful institute. See note 17.

${ }^{22}$ Respondent from a large, highly successful institute. See note 17.
} 
The suggestion that there are no 'markets' for scientific knowledge is debatable, since there are certainly markets for many sciencebased technologies. Yet, it seems that managers prefer to use arbitrary evaluation techniques to simplify dialogue between organizations.

\section{Credentialization}

The concept of credentialization emerged as a second key element in the assessment of research quality. If a research institute seeks professional legitimacy, it must conform to the norms that typify its particular community. In this case, managers insist that research groups observe scientific norms. As one programme coordinator put it:

Gaining a certain reputation calls for an external benchmark. We are not alone in this scientific world. In that sense, I think that external benchmarking and conforming to the academic standards is very important. Communities create common standards. (...) This is very similar to modern art. You can do it, but if it is not recognized by a community, you are out of the game. ${ }^{23}$

A second programme coordinator insisted that 'All scientists know that, and they should submit themselves to this process':

If they do not accept these rules, they become philosophers but not researchers. They had better say 'leave me alone; I want to sit on the top of my mountain and try to understand the world, but I do not care about sharing anything with anyone'. This is something of value, but has nothing to do with science. A scientist is someone who submits to these established processes, trying to create an accepted result. $^{24}$

With credentialization, then, comes established, refined, stabilized, and reproduced behaviour. Credentialization processes have both symbolic and pragmatic value. The first arises from the prestige and authority associated with peer recognition. The second consists in entitling the researcher to funding and status; and in giving his organization a way of evaluating his efficiency.

As a coordinator explained:

The research quality issue is very important because all external accreditation bodies judge our work on the basis of quality aspects. And accreditation is crucial for the amount of research time and research money we get from the board of the university and from the institute. ${ }^{25}$

\footnotetext{
${ }^{23}$ Respondent from a relatively small institute with a record of mixed success. See note 17 .

${ }^{24}$ Respondent from a large, successful institute. See note 17.

${ }^{25}$ Respondent from a large, successful institute. See note 17.
} 
Another research associate agreed:

There are multiple external evaluation bodies that sort of force us to look at quality all the time. These organizations help us to look at our work from an external perspective and they are important to evaluate our long-term strategy. Their accreditation offers us an impartial feedback on what we defined as being our ambition and on the actions we undertake to accomplish it. ${ }^{26}$

All the institutes we examined had a 'research fellow policy' to reward compliance with the organization's criteria. Thus:

Publishing internationally leads to research time and to the maintenance of 'fellow' status. There are two sorts of membership: fellows and associate fellows. For being a fellow, researchers need 5 credit points, whereas for being associate fellows they need 3 credit points. This is an accreditation procedure. The general rule is that fellows have $50 \%$ research time, while associate fellows, $30 \%{ }^{27}$

Credentialization helps individuals conform to quality standards. If a researcher fails to get 'fellow' status, he may fail to win research funds. As one research director put it bluntly:

As an institute we need to keep in mind that the quality we want to achieve is the quality we reward. Researchers need to stick to the system and to accept that this is the way we do things here. ${ }^{28}$

Credentialization can also be symbolic, as it distinguishes strategic choices defined by the process of rationalization, which can affect relationships between research organisations in a highly competitive field.

\section{Question III - How to Measure Quality? The ABC of Research Quality Assessment}

Answers to the question, 'How do you measure research quality? show that ISI journal rankings are the prevailing benchmarks. Clearly, their use signals a preference for measures that are observed worldwide. Research managers also specify quality representations - which we label as 'quality iconographies' - that are applied through what we call 'quality measurement machinery'.

\section{Quality iconographies}

Measurement assumes criteria. At one level, the categories of quality assessment are clear. As one research director explained:

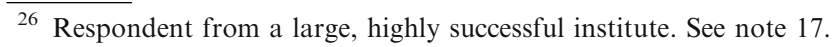

27 Respondent from a medium-sized, successful institute. See note 17.

${ }^{28}$ Respondent from a large, highly successful institute. See note 17.
} 
We measure the quality of research by assigning different quality labels to journals and book publications. There is a general internal agreement as regards the idea that articles are typically of higher quality than book chapters or books (the three categories we take into account). ${ }^{29}$

Apparently, since the quality referential becomes the quality reference, every other manifestation of quality goes unnoticed. So, 'researchers are free to write conference proceedings, books, book chapters and the like, as long as they publish one international article per year'. While there is pressure to publish in ISI journals, one research director admitted that 'there are certain areas that are underrepresented in the SSCI, and ... we rely on peers to get a feeling about what might be considered a top journal in that area'. In such cases, the institute lets its strategic ambitions infuse its research management. This also affects the choice of journals, which embodies a choice as to where, in disciplinary space, an institute wants to be known. At the same time, it retains the power to select alternative representations and to reward them accordingly.

\section{Quality measurement machinery}

Having an annual target meets with general agreement. But research managers recognize and rank success in particular ways. Notably, they rely upon ISI categories, and upon SCI and SSCI impact factors. Thus:

Our research target is at least one international article published in a refereed journal every year. There are three possible levels of performance: below the standard, standard, or above the standard. ${ }^{30}$

Typically, managers categorize publications in three groups of descending order of 'quality' ('A', 'B', and 'C'), as measured by disciplinary impact. However, the labels do not suit all equally:

We would all agree that the Academy of Management Journal is a better journal than the Journal of Management and that both are better than Strategic Management and Technological Analysis. But it is not unproblematic to sort them into $\mathrm{A}, \mathrm{B}$ and $\mathrm{C}$ classes. When we draw lines, there are journals that will be on two different sides of the fence. These lists are by definition intersubjective. ${ }^{31}$

\footnotetext{
29 Respondent from a large, highly successful institute. See note 17.

30 Respondent from a small institute with a record of mixed success. See note 17.

31 Respondent from a large, highly successful institute. See note 17.
} 
In most institutes, a researcher's appearance in ' $\mathrm{A}$ ', ' $\mathrm{B}$ ', and ' $\mathrm{C}$ ' categories is extremely important to professional advancement. Thus:

A researcher needs 14 points to become a fellow. An article in an A-type journal (corresponding to the top $10-15 \%$ of SSCI journals) confers 10 points. A B-type journal (corresponding to the top $50 \%$ of SSCI journals) confers 6 points. And a C-type, which gives 2 points, [covers] the remaining SSCI list and also contributions to books (providing these are refereed, internationally published, and written in English). ${ }^{32}$

This system is clearly problematic in that these categories imply distinctions that are neither trivial nor obvious. Conversely, the system is open to misunderstanding, and possible misuse.

\section{Question IV - The Effects of Assessing Quality: Opportunities and Threats}

Research managers see both positive and negative features in these assessment procedures. At one level, they have fuelled a sense of urgency and direction, prompting researchers to reframe expectations and methods. On the other hand, changes in orientation are driven not by the logic of the discipline, but by what seem like external market forces:

Were these pressures absent, we would not be putting such a strong effort on quality issues. These external pressures did really help increase productivity and quality. I really think it has been helpful. At our institute, publications doubled in the past five years as compared to the five-year period before that. ${ }^{33}$

For researchers, the experience has proved a mixed blessing:

(...) publishing in those [SCI and SSCI] outlets became a survival strategy, as the selection environment is pushing us into that direction. Besides, publishing in top journals is helpful as it provides us with a very clear purpose, quality standards, and ideas as to how to guide the research group for free. ${ }^{34}$

In this discipline, at least, Dutch researchers have accepted these rules in a pragmatic fashion. Possibly, their arbitrary features are softened by the acceptance of a neutral norm:

English peer-reviewed articles have become the [quality] norm, while most of the rest is not very much appreciated in the current environment. The other mediums are not valueless, but there is very little institutional reward for them. As in any

\footnotetext{
32 Respondent from a large, highly successful institute. See note 17.

33 Respondent from a large, successful institute. See note 17.

34 Respondent from a large, highly successful institute. See note 17.
} 
other organization, one is expected to follow those norms, at least to a large degree. (...) If we seek to spend our energy well, we should focus on the commonly declared important outlets - the journal articles - while assigning little energy to those that are marginal in terms of audiences. ${ }^{35}$

Nonetheless, adhering to these criteria may well curb a researcher's choice of topic or problem. Are researchers resigned to the prospect of a future dominated by such performance criteria?

In their responses, most managers see quality assessments as fragile, rather than flawless. Most acknowledge that assessing quality is neither unproblematic nor uncontested. Several are sceptical as to whether quality research will actually result from the setting of short-term targets for intrinsically long-term and unpredictable projects. Researchers may be forced to fabricate outputs that are recognizable, and thus rewardable. Such pressures may well interfere with critical reflection. As one manager put it:

The current system forces people to publish quickly, to have a short-term idea about publications, or short-term publication strategies. Thus, the current assessment and incentive system is demotivating for it leads to a short-term vision, which forces researchers to produce things they are neither happy with, nor associate with quality. The translation of quality and productivity elements into this system for rewarding quality demotivates research quality. ${ }^{36}$

Current assessment systems may promote haste at the expense of quality, and reward behaviour that gives the greatest measurable output at the lowest risk. Research assessment conducted along these lines may certainly be at odds with the disinterested search for knowledge. Worse, it can lead to what one manager called a 'growing mimicry of research'.

Since researchers are being trained and socialized in a particular way, they will tend to reproduce it, which can lead to conservative behaviour... . If one tries to go one step too far, or to bring in different disciplines or research angles to enrich one's ideas, one will have fewer chances to publish, which might destroy intrinsic creativity. Small, stepby-step improvements are valued more than dramatic breakthrough approaches. This means that we might spoil some people's talent, if this talent does not fit the system. ${ }^{37}$

In this event, the act of evaluation itself may suppress creativity:

It is far more attractive to repeat a trick to get a higher output. Thus, do not move too much; sit down on your golden egg, and make hundreds of them in all different colours. ${ }^{38}$

\footnotetext{
${ }^{35}$ Respondent from a large, highly successful institute. See note 17.

36 Respondent form a relatively small institute with a record of mixed success. See note 17 .

37 Respondent from a large, highly successful institute. See note 17.

${ }^{38}$ Respondent from a medium-sized, successful institute. See note 17.
} 
The ambivalence of managers toward quality assessment seems to produce neither uncompromising support nor disruptive disagreement. The quality agenda is not adopted without criticism. Instead, it invites closer examination.

\section{LOOKING FORWARD}

The goal of our study was to unravel practices of knowledge management in a particular discipline at a particular place and time. Our interviews have led to several conclusions. First, the act of setting quality standards reflects a managerial view of knowledge as a measurable, accumulative, and marketable commodity. ${ }^{39}$ Managerial motives for evaluation proceed from demands for (a) rationalization and (b) credentialization, which lead to (c) the identification of 'quality iconographies' and (d) the use of 'machinery' of measurement. Rationalization answers the call for discrimination, selection, and the efficient allocation of resources. Credentialization reflects the desire to introduce and police the 'rules of the game'. 'Quality iconographies' - incorporate measures that function as counselling devices. 'Quality measurement machinery' - typically, ISI data - is believed to reflect a standardized measure of quality, and is thus used to convert points into status.

Evidently, quality is measured by those with power to define the terms. ${ }^{40}$ As the language of evaluation is defined by managers, it works as a "certification of comfort'. ${ }^{41}$ This points to what $\mathrm{Xu}$ calls a spider web - the use of definitions that have no existence separate from the discourse that establishes them. ${ }^{42}$ Xu's application of met-

\footnotetext{
39 This treatment of knowledge reminds us of what $\mathrm{Xu}$ calls the snowball metaphor. Knowledge grows like a snowball, with constructs that gain or lose meaning over time through purposeful adding to - or subtracting from - what's there. See Q. Xu, 'On the Way to Knowledge: Making a Discourse at Quality', Organization, 7 (3), (2000), 427-453.

${ }^{40}$ K.E. Weick, 'Quality Improvement: A Sensemaking Perspective', in R.E. Cole and W.R. Scott (eds.), The Quality Movement and Organization Theory (Thousand Oaks: Sage, 2000), 155-172.

${ }^{41}$ Power, op. cit. note 6.

${ }^{42} \mathrm{Xu}$, op. cit. note 39 . The spider web metaphor relates the meaning of a concept to the way it is used. The spider web captures a relational way of being, where links (not 'things') constitute reality.
} 
aphor reflects the difference between an objectivist, cognitive, and representational approach and a 'process approach' to the production of knowledge. ${ }^{43}$ These contrasting approaches are based on what Scott Cook and John Seely Brown have called 'epistemologies-of-possession' and 'epistemologies-of-practice'. ${ }^{44}$ Today, the activity of research assessment draws upon an oversimplified view of knowledge production. But even where managers see a 'spider web' at work, they seemingly fail to recognise its full implications.

What is clear is that quality management deserves active analysis, going beyond a simple calculus of ISI scores. The way forward is reflected in a call by Andrew Hargadon and Angelo Fanelli to distinguish between 'knowledge as action' and 'knowledge as possibility for constructing novel organizational actions, ${ }^{45}$ Looking at the quality system from a representational - or ISI standpoint alone is inherently limited. Systems of measurement reflect the ways in which managers negotiate between what systems wish and what researchers do. However, as Mark Zbaracki has argued, the rhetoric and practice of management mutually constitute each other. ${ }^{46}$

No-one disputes that quality measurements can affect the nature of knowledge production. Respondents say that the use of indicators has led to increased publication in the English language, and in SSCI journals; and has also led to the hiring of researchers who make their way to the upper tiers of the SSCI. The practice, while clearly beneficial in many respects, can also lead to mimicry, opportunism, conservatism, and research for the sake of publication. ${ }^{47}$

Managers can repair these unintended side effects by considering what researchers consider relevant. The fact that - in this

\footnotetext{
${ }^{43}$ For example, U. Schultze and C. Stabell, 'Knowing What You Don't Know? Discourses and Contradictions in Knowledge Management Research', Journal of Management Studies, 41 (4), (2004), 549-573; R. Chiva and J. Alegre, 'Organizational Learning and Organizational Knowledge: Towards the Integration of Two Approaches', Management Learning, 36 (1), (2005), 49-68.

${ }^{44}$ S.D.N. Cook and J.S. Brown, 'Bridging Epistemologies: The Generative Dance between Organizational Knowledge and Organizational Knowing', Organization Science, 10 (4), (1999). See also the epistemological distinction made by Schultze and Stabell, op. cit. note 43 .

45 A. Hargadon and A. Fanelli, 'Action and Possibility: Reconciling Dual Perspectives of Knowledge in Organizations', Organization Science, 13 (3), (2002), 290-302.

${ }^{46}$ M.J. Zbaracki, 'The Rhetoric and Reality of Total Quality Management', Administrative Science Quarterly, 43 (3), (1998), 602-636.

${ }^{47}$ See Peter Weingart, 'Impact of Bibliometrics upon the Science System: Inadvertent Consequences?' Scientometrics, 62 (1), (2005), 117-131.
} 
discipline, at this time, and in this place - they may not be doing so, points to the fact that most academic organizations work to commonly accepted standards. Differences between Dutch institutes of business studies are relatively minor. They all agree that quality is taken seriously in line with received principles.

To reconsider what these principles should be, we propose in Figure 1 a different approach - one that gives researchers a shopping list of relevant issues and relationships. It also tells researchers and managers how to avoid a simplistic 'against management' or 'for management' response. A balanced understanding is needed to distinguish between research as knowledge work, and management as method of appraisal. The one clearly shapes the other. Figure 1 labels the circular relationship between research and management as following arrows of 'representation' and 'constitution', respectively.

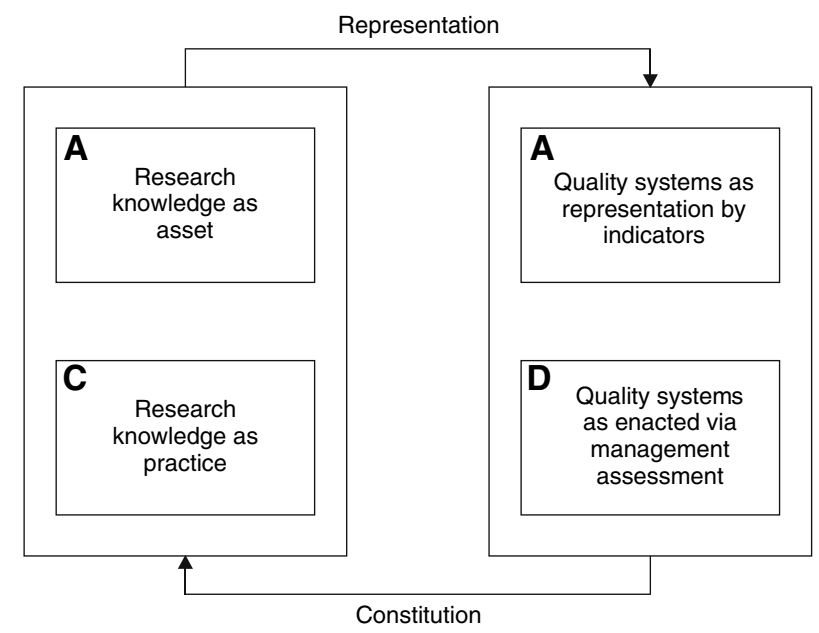

Figure 1. Connections between Knowledge Production and Quality Assessment

Currently, research quality management is mostly limited to counting and categorizing articles and books. However, quality involves more than performance rankings. Figure 1 emphasizes the distinction between 'knowledge as asset' and 'knowledge as practice'. Our findings suggest that accurate assessment of research quality is unachievable if the process of evaluation does not go beyond management rhetoric that relies heavily on publication counts and ISI data. 


\section{CONCLUSION}

Our study has led us to three broad conclusions. First, it has reinforced the widely held view that the practice of assessing research quality is problematic. 'Quality' concepts are shaped by management practices that are pragmatic, contested, and socially-embedded. Interpreting quality, primarily in terms of quantitative and normative standards, leads to downplaying, if not ignoring the situated and negotiated character of scholarship. Second, the present use of quality assessment in the discipline of business studies in The Netherlands draws upon an oversimplified view of knowledge, what we call an 'epistemology of possession'. ${ }^{48}$ In focusing on unsophisticated performance indicators, it privileges 'knowledge that is (organizationally) known'. As such, it dissociates knowledge from the knowing subject, since it does not draw on knowledge, but rather focuses on representations of knowledge, as seen in publications and their ranking. In accepting these 'constitutions' uncritically, management can easily neglect or override dynamic and emergent aspects of knowledge production that are essential to creativity and innovation.

Third, to ask these questions exclusively from the standpoint of researchers, or from that of the management, is dangerously shortsighted. ${ }^{49}$ The challenge confronting academic management is not to develop yet more elaborate scientometrics, however informative they may appear, but rather to produce a balanced understanding of the different practices involved in research. ${ }^{50}$ Our study has considered only one geographical and disciplinary reality, where 'representation' - through science indicators - retains a central importance. How good a representation of quality that gives, depends on how it is embedded in practice, and how that practice is appropriated in the library and laboratory. Certainly, managers must weigh the possibility that an over-reliance on ISI data may produce assessments that are fatally flawed.

\footnotetext{
${ }^{48}$ Cook and Brown, op. cit. note 44.

${ }^{49}$ C.f. J. Barry, J. Chandler, and H. Clark, 'Between the Ivory Tower and the Academic Assembly Line', Journal of Management Studies, 38 (1), (2001), 87-101.

${ }^{50}$ For example, see M. Parker and D. Jary, 'The McUniversity: Organization, Management and Academic Subjectivity', Organization, 2 (2), (1995), 319-338, A. Wilts, 'Forms of Research Organisation and their Responsiveness to External Goal Setting, Research Policy, 29 (6), (2000), 767-781, and Morley, op. cit. note 1.
} 


\section{ACKNOWLEDGEMENTS}

The authors gratefully acknowledge the many respondents who spent several hours exploring the peculiarities of research management. They would also like to thank the Editor of Minerva and three anonymous referees for their constructive comments.

\section{ABOUT THE AUTHORS}

Celio A.A. Sousa has a PhD in Management Sciences from Radboud University in Nijmegen. His research interests include management rhetoric and practice $v i s-\grave{a}$-vis scientific practice. He is now employed as a Human Resource Manager in a commercial firm in Porto, Portugal.

Paul H.J. Hendriks is a Professor of Business Administration at Radboud University. His research considers structures and networks in connection with a knowledge-based view of organizations.

Nijmegen School of Management

Radboud University Nijmegen

PO Box 9108

Nijmegen, $6500 \mathrm{HK}$

The Netherlands

E-mail: p.hendriks@fm.ru.nl 